\title{
CULTIVO IN VITRO DE EIXOS EMBRIONÁRIOS DE PARICÁ ${ }^{1}$
}

\author{
In vitro culture of paricá embryonic axes
}

\author{
Iulla Naiff Rabelo de Souza Reis², Osmar Alves Lameira ${ }^{3}$, Iracema Maria Castro Coimbra Cordeiro $^{4}$, \\ Carla Vanessa Borges Castro ${ }^{5}$, Allan Guerreiro Carneiro ${ }^{6}$
}

\begin{abstract}
RESUMO
Objetivou-se, neste trabalho, avaliar a influência do meio de cultura MS normal e com as concentrações dos sais reduzidas à metade ( $\left.1 \frac{1}{2} \mathrm{MS}\right)$, a presença de ácido giberélico $\left(\mathrm{AG}_{3}\right)$ e de ácido cítrico em eixos embrionários de paricá cultivados in vitro. Os eixos embrionários foram extraídos das sementes e inoculados em meio de cultura básico MS e 1/2 MS, suplementados ou não com ácido cítrico $\left(1 \mathrm{~g} . \mathrm{L}^{-1}\right)$ e com $\mathrm{AG}_{3}\left(3 \mathrm{mg} . \mathrm{L}^{-1}\right)$, constituindo 6 tratamentos e 7 repetições. Os eixos embrionários de paricá podem ser cultivados em meio MS com metade das concentrações dos sais, não sendo necessária a adição de ácido cítrico, e a presença de 3 mg. $\mathrm{L}^{-1}$ de $\mathrm{AG}_{3}$ afetou o desenvolvimento das plântulas de paricá.
\end{abstract}

Termos para indexação: Ácido giberélico, ácido cítrico, Schizolobium parayba var. amazonicum.

\section{ABSTRACT}

The aim of this study was to evaluate the influence of normal MS culture medium and at half strength of its salts $(1 / 2$ MS), the presence of gibberellic acid $\left(\mathrm{GA}_{3}\right)$ and citric acid on the in vitro culture of paricá embryonic axes. The embryonic axes were extracted from seeds and inoculated on basic MS and $1 / 2$ MS culture media, supplemented or not with citric acid ( 1 g.L.- $\left.{ }^{-1}\right)$ and GA G $_{3}\left(3 \mathrm{mg} . \mathrm{L}^{-1}\right)$, constituting 6 treatments and 7 replications. The embryonic axes of paricá may be cultivated on MS medium at half strength of its salts, the addition of citric acid not being necessary, and the presence of $3 \mathrm{mg} . \mathrm{L}^{-1} \mathrm{GA}_{3}$ affected the development of paricá seedling.

Index terms: Gibberellic acid, citric acid, Schizolobium parayba var. amazonicum.

(Recebido em 25 de maio de 2007 e aprovado em 31 de maio de 2008)

\section{INTRODUÇÃO}

O Schizolobium parahyba var. amazonicum (Huber ex Ducke) Barneby, vulgarmente conhecido como paricá, ocorre na Amazônia brasileira, venezuelana, colombiana, peruana e boliviana. No Brasil, é encontrado nos estados do Amazonas, Pará, Mato Grosso e Rondônia, em solos argilosos de florestas primárias e secundárias, tanto em terra firme quanto em várzea alta (SOUSA et al., 2005). É uma espécie que tem despertado interesse entre produtores rurais e madeireiros, devido ao valor comercial da madeira para a produção de laminados de excelente qualidade, como também pelo crescimento rápido da espécie, principalmente nos primeiros anos (FALESI \& SANTOS, 1996).

Dependendo da origem das sementes do paricá, constatam-se problemas de contaminação por bactérias e, considerando que o embrião está alojado numa região estéril da semente, a cultura de embriões e/ou eixos embrionários pode representar uma alternativa para a produção in vitro de plântulas de paricá. Segundo Pasqual \& Pinto (1988), embriões cultivados in vitro permitem, entre outras coisas, estudar as necessidades nutricionais e físicas para o seu desenvolvimento, superar a dormência em certos tipos de sementes e testar a viabilidade das sementes. Acrescenta-se a isso o fato de que tecidos embrionários são excelentes explantes para serem usados em estudos, visando a propagação clonal in vitro em virtude de sua natureza juvenil e alto potencial regenerativo (PIERIK, 1990). Um importante aspecto da cultura de embriões é definir um meio de cultura que possa sustentar o seu crescimento e desenvolvimento (HU \& FERREIRA, 1998), sendo que, para espécies lenhosas, composições mais diluídas em macronutrientes do meio MS têm

\footnotetext{
${ }^{1}$ Parte da Dissertação apresentada à Universidade Federal Rural da Amazônia - UFRA. Av. Tancredo Neves, 2501, Montese, Belém-PA, CEP 66077-530, pelo primeiro autor.

²Engenheira Agrônoma, Doutoranda em Fisiologia Vegetal - Laboratório de Cultura de Tecidos II - Instituto de Biotecnologia Aplicada à Agropecuária Universidade Federal de Viçosa/UFV - Avenida PH Rolfs, s/n - Campus Universitário - 36570-000 - Viçosa, MG - naiff_agro@yahoo.com.br ${ }^{3}$ Engenheiro Agrônomo, Doutor, Pesquisador - Pavilhão de Pesquisa - Embrapa Amazônia Oriental - Travessa Doutor Enéas Pinheiro, s/n - Cx. P. 48 66095-100 - Belém, PA - osmar@cpatu.embrapa.br

${ }^{4}$ Engenheira Florestal, Doutora - Tramontina Belém S.A. - Travessa Quintino Bocaiúva, 1145/604 - 66053-240 - Belém, PA - mgti@amazon.com.br ${ }^{5}$ Engenheira Agrônoma, Mestre - Universidade Federal Rural da Amazônia/UFRA - Passagem Tito Franco, 10A - Souza - 66613-580 - Belém, PA carlinhaufra@hotmail.com

${ }^{6}$ Cientista da Computação, Mestrando em Ciência da Computação - Departamento de Informática/DPI - Laboratório de Pós-Graduação - Universidade Federal de Viçosa/UFV - Avenida PH Rolfs, s/n - Campus Universitário - 36570-000 - Viçosa, MG - allanguerreiro@yahoo.com.br
} 
apresentado ótimos resultados (GRATTAPAGLIA \& MACHADO, 1998).

Existem muitas informações sobre os efeitos do ácido giberélico $\left(\mathrm{AG}_{3}\right)$ em embriões maduros extraídos de sementes dormentes que não germinam mesmo em condições ideais (ALVARENGA, 1990), e segundo Kochba et al. (1974), a presença de $\mathrm{AG}_{3}$, no meio de cultura, proporciona a iniciação de uma zona meristemática radicular ou estimula o desenvolvimento de uma zona radicular existente. Cordeiro et al. (2002), ao estudar a germinação de sementes de paricá, verificaram que não houve necessidade de aplicação exógena de $\mathrm{AG}_{3}$ ao meio de cultivo.

A oxidação dos explantes tem sido um dos principais entraves ao cultivo in vitro de espécies lenhosas, fato investigado por Cordeiro (2002), que verificou que o ácido ascórbico e o ácido cítrico, aliados à redução do nitrato de amônio, promoveram uma redução significativa da oxidação de explantes de paricá. Segundo Fortes (1992), o processo oxidativo em espécies lenhosas pode estar relacionado a certos eventos, como intensidade de luz, fotoperíodo, temperatura e a concentração dos sais minerais do meio de cultura, especialmente o nitrogênio, a partir do nitrato de amônio.

Objetivou-se, neste trabalho, testar os efeitos do meio MS normal e com metade das concentrações dos sais, a presença de ácido giberélico $\left(\mathrm{AG}_{3}\right)$ e de ácido cítrico sobre o cultivo in vitro de eixos embrionários de paricá, visando a obtenção de plântulas para posterior utilização em micropropagação.

\section{MATERIALE MÉTODOS}

O experimento foi desenvolvido no laboratório de Biotecnologia e Recursos Genéticos da Embrapa Amazônia Oriental (Belém/PA). As sementes de paricá procedentes do município de Ji-Paraná, no Estado de Rondônia, foram obtidas através da Associação das Indústrias Exportadoras de Madeiras do Estado do Pará (AIMEX).

As sementes de paricá foram escarificadas mecanicamente com lixa e colocadas em becker com 100 $\mathrm{mL}$ de água e submetidas a várias lavagens em água corrente e detergente comercial. Em câmara de fluxo laminar, as sementes foram desinfestadas em álcool comercial $70 \%$ por três minutos e imersas em solução de hipoclorito de sódio $(\mathrm{NaOCl})$ a $3 \%$, por vinte minutos, sendo cinco minutos em agitação. Posteriormente, foram lavadas quatro vezes em água destilada e autoclavada e imersas em água destilada com temperatura em torno de $70^{\circ} \mathrm{C}$, na qual permaneceram por 24 horas. Decorrido esse tempo, retirou-se o tegumento das sementes e, então fez- se a extração dos eixos embrionários, os quais foram distribuídos em placas de Petri, contendo papel filtro umedecido com água destilada e autoclavada para evitar a desidratação dos mesmos e, posteriormente foram inoculados em frascos contendo meio de cultura básico MS (MURASHIGE \& SKOOG, 1962), em concentrações normais (MS) e concentrações dos sais reduzidas a metade ( $\left.1 \frac{2}{2} \mathrm{MS}\right), 30$ g.L $\mathrm{L}^{-1}$ de sacarose, 6 g.L. $\mathrm{L}^{-1}$ de agar, adicionados ou não de 1 g.L $\mathrm{L}^{-1}$ de ácido cítrico $(\mathrm{AC})$ e de 3 $\mathrm{mg} . \mathrm{L}^{-1}$ de ácido giberélico $\left(\mathrm{AG}_{3}\right) . \mathrm{O} \mathrm{pH}$ do meio de cultura foi ajustado para 5,8 , antes da autoclavagem. Os meios de cultura foram distribuídos na quantidade de $40 \mathrm{~mL}$ por frasco e autoclavados a $120^{\circ} \mathrm{C}$ e 1,2 atm, durante 20 minutos. As culturas foram mantidas em sala de crescimento sob temperatura de $24 \pm 1^{\circ} \mathrm{C}$, fotoperíodo de 16 horas de luz branca fria e irradiância de $25 \mu \mathrm{mol} \mathrm{m} \mathrm{m}^{-2} \mathrm{~s}^{-1}$. Os tratamentos utilizados foram: $1 / 2 \mathrm{MS} ; 1 / 2 \mathrm{MS}+\mathrm{AC} ; 1 / 2$ $\mathrm{MS}+\mathrm{AC}+\mathrm{AG}_{3} ; \mathrm{MS} ; \mathrm{MS}+\mathrm{AC} ; \mathrm{MS}+\mathrm{AC}+\mathrm{AG}_{3}$

$\mathrm{O}$ delineamento experimental utilizado foi inteiramente casualizado, com seis tratamentos e sete repetições, sendo que cada repetição foi representada por um frasco contendo três eixos embrionários. As seguintes variáveis foram avaliadas semanalmente: comprimento da haste caulinar; comprimento da raiz primária; número médio de raízes; peso da matéria fresca da haste caulinar; peso da matéria fresca do sistema radicular; e porcentual de explantes que apresentaram o primeiro par de folhas.

Para análise estatística foram considerados os dados coletados aos 30 dias de cultivo, os quais foram submetidos à análise de variância e quando houve efeito significativo, as médias foram comparadas pelo teste de Tukey, ao nível de 5\% de probabilidade através do programa estatístico Sisvar (FERREIRA, 2002). Os dados de número de raízes e porcentual de explantes que apresentaram o primeiro par de folhas foram transformados para $(X+0,5)^{1 / 2}$ e $\operatorname{arcsen}(X / 100)^{1 / 2}$, respectivamente.

\section{RESULTADOS E DISCUSSÃO}

Na Figura 1A é possível visualizar o eixo embrionário no momento da inoculação. A germinação teve início no primeiro dia de cultivo, quando foi observado o alongamento do eixo hipocótilo-raiz (Figura 1B), sendo que o desenvolvimento ocorreu de forma diferenciada, de acordo com a presença ou não de $\mathrm{AG}_{3}$. Em meios de cultura sem a adição desse regulador de crescimento, foi verificado, a partir do terceiro dia de cultivo, a formação da radícula, o alongamento do hipocótilo e a visualização da plúmula (Figuras 1C e 1D). 
Aos 10 dias, foi observada a formação da raiz primária e o desenvolvimento inicial da plúmula e aos 15 dias, verificou-se a formação de raízes secundárias, os primórdios foliares, bem como a modificação na coloração do hipocótilo, que se tornou esverdeada (Figuras 1E e 1F). A partir do vigésimo quinto dia de cultivo, foi constatado o aparecimento de mais raízes secundárias e a formação da primeira folha, e com 30 dias foi observado o alongamento do epicótilo e das folhas, com a formação da plântula (Figuras $1 \mathrm{G}$ e $1 \mathrm{H}$ ). Nos meios de cultura onde houve a adição de $\mathrm{AG}_{3}$, o processo germinativo dos embriões ocorreu de forma similar ao anterior somente até o terceiro dia de cultivo, uma vez que não houve a formação da raiz primária. Aos 15 dias de cultivo, foi verificada a formação de raízes adventícias, com pouco desenvolvimento do epicótilo e a partir do vigésimo quinto dia, observou-se o alongamento do hipocótilo, no entanto, não ocorreu o desenvolvimento da plúmula (Figuras 1I e 1J).

De acordo com análise de variância (Tabela 1) não houve diferença estatística entre os tratamentos utilizados para o comprimento da haste caulinar, enquanto que, para comprimento da raiz principal e número de raízes, as diferenças observadas foram altamente significativas.

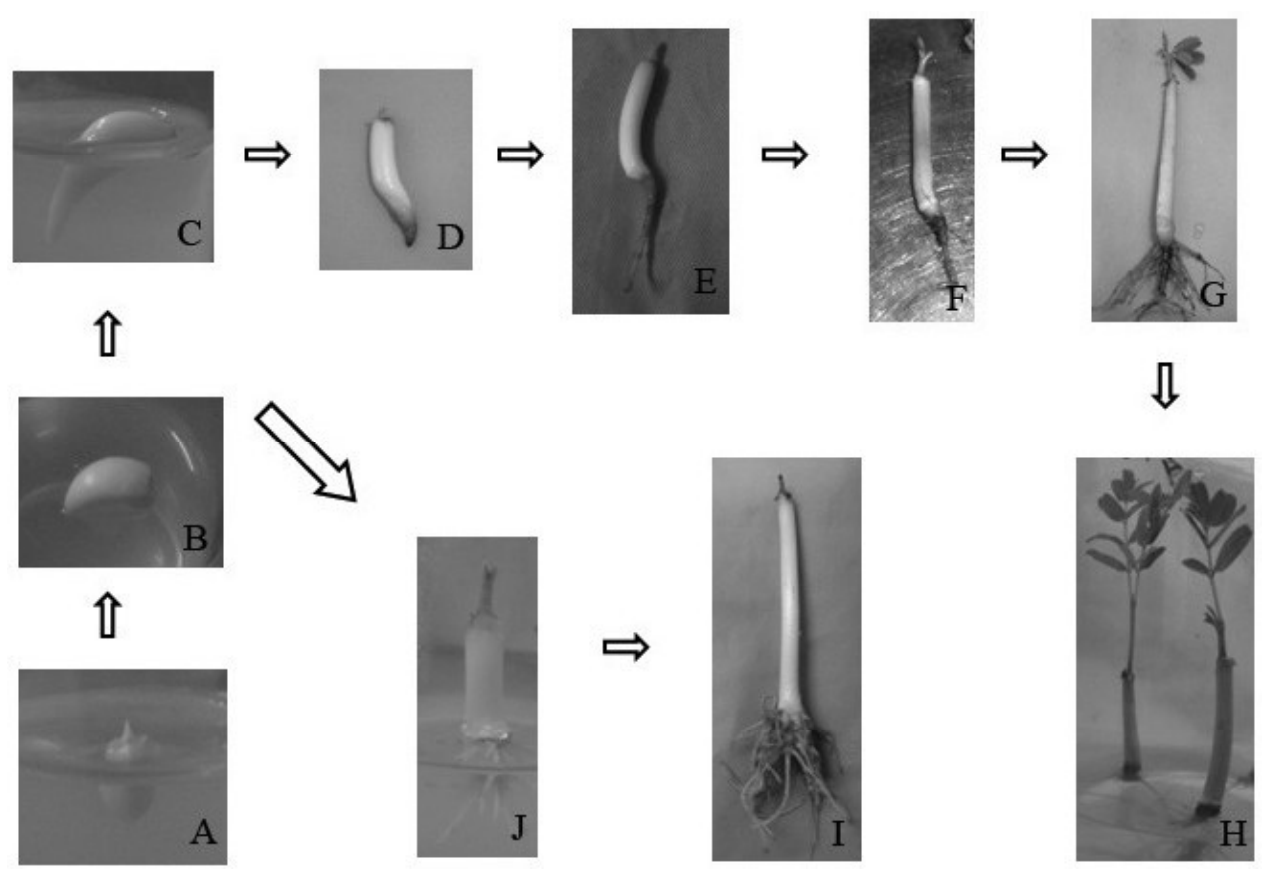

Figura 1 -Eixo embrionário de paricá inoculado em meio 1⁄2 MS (A); com 1 (B); 3 (C); 5 (D); 10 (E); 15 (F); 20 (G) e 25 (H) dias de cultivo; e eixo embrionário cultivado na presença de $\mathrm{AG}_{3} \operatorname{com} 15$ (I) e 25 (J) dias.

Tabela 1 - Resumo da análise de variância para comprimento da haste caulinar (CHC), comprimento da raiz principal (CRP) e número de raízes (NR).

\begin{tabular}{lccccccc}
\hline \multicolumn{1}{c}{ C.V. } & G.L. & \multicolumn{3}{c}{ Q.M. } & \multicolumn{2}{c}{ F } \\
\hline Tratamentos & 5 & CHC & CRP & NR $^{1}$ & CHC & CRP & NR $^{1}$ \\
Resíduo & 36 & 0,2424 & 1,494 & 6,2478 & 0,68 NS & $15,48 * *$ & $17,9 * *$ \\
\hline Média & & 3,3545 & 0,965 & 0,3490 & & & \\
\hline
\end{tabular}

NS e **: Não significativo e significativo, ao nível de $1 \%$ de probabilidade, pelo teste $\mathrm{F}$, rescpectivamente. ${ }^{1}$ Dados transformados para $(X+0,5)^{1 / 2}$ 
Observa-se, na Figura 2A que, na ausência de $\mathrm{AG}_{3}$, houve o desenvolvimento normal da parte aérea, entretanto, nos tratamentos em que esse regulador de crescimento foi adicionado ao meio de cultura, as plântulas geralmente apresentaram alongamento do hipocótilo com coloração bege-amarelado, e com pouco desenvolvimento do epicótilo (Figura 2B), indicando que esse regulador de crescimento, na concentração estudada ( $\left.3 \mathrm{mg} . \mathrm{L}^{-1}\right)$ influenciou negativamente o cultivo in vitro de eixos embrionários de paricá.

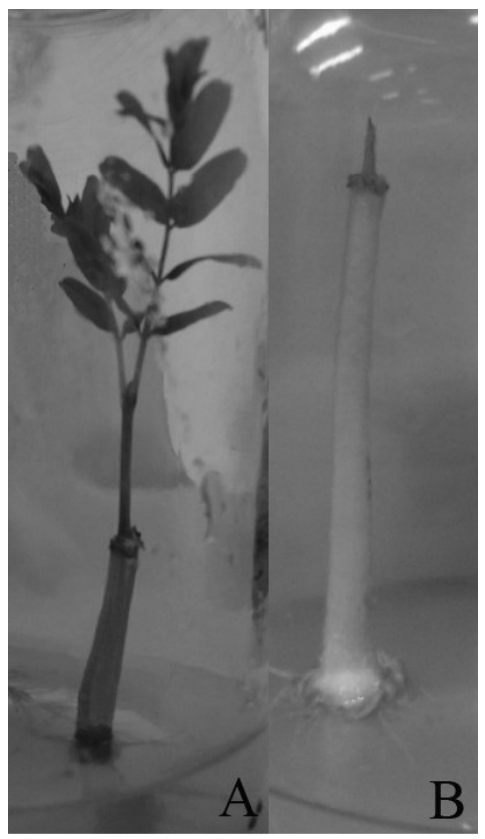

Figura 2 - Plântulas oriundas de eixos embrionários de paricá cultivados em meio MS, com as concentrações dos sais reduzidas à metade, na ausência $(\mathrm{A})$ e presença de 3 mg.L $L^{-1}$ de $\mathrm{AG}_{3}(\mathrm{~B})$.

No trabalho de Cordeiro et al. (2002), não houve relatos de desenvolvimento anormal das plântulas de paricá obtidas a partir de sementes na presença de 3 mg.L $\mathrm{L}^{-1}$ de $\mathrm{AG}_{3}$. Assim, a resposta obtida no presente estudo pode estar relacionada com a própria condição fisiológica das sementes, além da interação do $\mathrm{AG}_{3} \mathrm{com}$ os demais hormônios contidos no embrião. É importante ressaltar que somente a concentração de $3 \mathrm{mg} \cdot \mathrm{L}^{-1}$ de $\mathrm{AG}_{3}$ não é suficiente para afirmar a influência desse regulador de crescimento no desenvolvimento dos eixos embrionários de paricá, havendo, para isso, a necessidade de estudos de menores concentrações de $\mathrm{AG}_{3}$ na referida espécie.

Em nogueira (Juglans regia L.), $2 \mathrm{mg} \mathrm{L}^{-1}$ de $\mathrm{AG}_{3} \mathrm{em}$ combinação com outros reguladores de crescimento promoveu um maior porcentual de germinação de embriões (KAUR et al., 2006). No trabalho de Ribeiro et al. (2000), a suplementação de $0,01 \mathrm{mg} . \mathrm{L}^{-1}$ de $\mathrm{AG}_{3}$ ao meio $\mathrm{MS}$ favoreceu o desenvolvimento e o crescimento de embriões do híbrido Citrus limonia Osb. x Poncirus trifoliata (L.) Raf. cultivados in vitro. Chagas et al. (2005) constataram que o maior comprimento da parte aérea e da raiz de plântulas oriundas de embriões globulares de citros foi na presença de 0,1 e $1 \mathrm{mg} . \mathrm{L}^{-1}$ de $\mathrm{AG}_{3}$, combinado com 2 g.L.de carvão ativado.

Os resultados referentes ao comprimento médio da raiz principal e número médio de raízes são apresentados na Tabela 2.

Os maiores comprimentos da raiz principal ocorreram nos tratamentos na ausência de $A_{3}$, não havendo diferença significativa entre si, contudo os maiores números de raízes foram observados nas plântulas oriundas de eixos embrionários cultivados em meio $1 / 2 \mathrm{MS}$ e MS normal suplementados com esse regulador de crescimento, com 21,83 e 17,61 raízes em média, respectivamente (Tabela 2 ).

Nos tratamentos em que houve suplementação com $\mathrm{AG}_{3}$, ficou evidenciado visualmente que houve o atrofiamento da raiz principal, entretanto, a planta apresentou um sistema radicular mais denso, com formação de inúmeras raízes adventícias (Figura 3A e 3B). Isso demonstra que o $\mathrm{AG}_{3}$ alterou o padrão de desenvolvimento dos embriões zigóticos de paricá, tanto da parte aérea quanto do sistema radicular.

De acordo com Carvalho et al. (1998), a adição de $\mathrm{AG}_{3}$ afetou o processo de emergência das raízes em embriões de cafeeiro (Coffea arabica L. cv. Acaiá). George (1993) afirmou que a presença de $\mathrm{AG}_{3}$ no meio de cultura, freqüentemente impede ou diminui a formação de raízes, principalmente, se a concentração de $\mathrm{AG}_{3}$ utilizada promover o crescimento de meristemas isolados ou extremidades de brotações, porém esse autor também citou trabalhos em que o $\mathrm{AG}_{3}$ promoveu um aumento na formação de raízes em ameixa (Prunus salicina Lindl.) e café (Coffea arabica L). 
Tabela 2 -Comprimento médio da raiz principal e número médio de raízes por plântula de paricá obtida a partir de eixos embrionários de paricá inoculados em meio MS.

\begin{tabular}{lcc}
\hline $\begin{array}{c}\text { Composição do meio de } \\
\text { cultura }\end{array}$ & $\begin{array}{c}\text { Comprimento médio da } \\
\text { raiz principal }(\mathrm{cm})\end{array}$ & $\begin{array}{c}\text { Número médio } \\
\text { de raiz }\end{array}$ \\
\hline $1 / 2 \mathrm{MS}$ & $1,44 \mathrm{a}$ & $8,21 \mathrm{~b}$ \\
$1 / 2 \mathrm{MS}+\mathrm{AC}$ & $1,43 \mathrm{a}$ & $8,27 \mathrm{~b}$ \\
$1 / 2 \mathrm{MS}+\mathrm{AC}+\mathrm{AG}_{3}$ & $0,49 \mathrm{~b}$ & $21,83 \mathrm{a}$ \\
$\mathrm{MS}$ & $1,55 \mathrm{a}$ & $4,53 \mathrm{~b}$ \\
$\mathrm{MS}+\mathrm{AC}$ & $1,43 \mathrm{a}$ & $8,30 \mathrm{~b}$ \\
$\mathrm{MS}+\mathrm{AC}+\mathrm{AG}_{3}$ & $0,67 \mathrm{~b}$ & $17,61 \mathrm{a}$ \\
\hline
\end{tabular}

Médias seguidas por letras distintas entre si comparam os tratamentos, ao nível de 5\% de probabilidade pelo Teste de Tukey. MS: meio de cultura Murashige \& Skoog (1962); AC: ácido cítrico; $\mathrm{AG}_{3}$ : ácido giberélico.

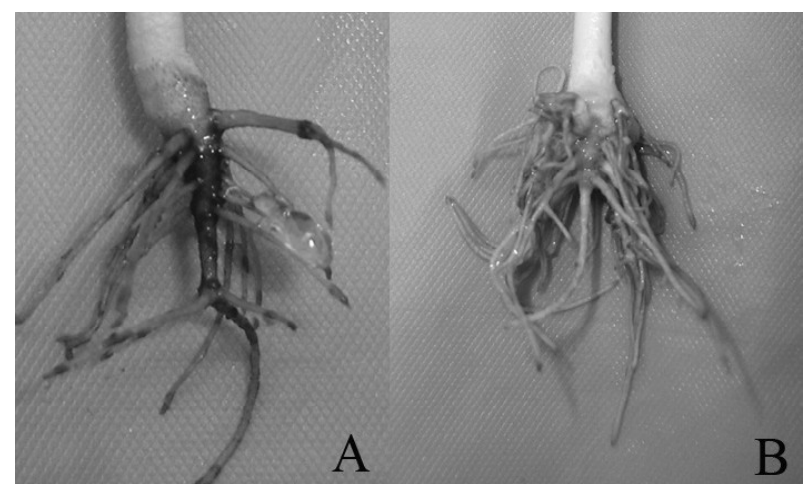

Figura 3 - Aspectos das raízes de plântulas oriundas de eixos embrionários de paricá, cultivados em meio MS, contendo as concentrações dos sais reduzidas à metade, na ausência (A) e presença de $\mathrm{AG}_{3}(\mathrm{~B})$.

As plantas lenhosas acumulam polifenóis e produtos de oxidação, como melanina, suberina, lignina, cutina e calose em torno da superfície excisada, modificando a composição do meio de cultivo e a absorção de metabólitos (ANDRADE et al., 2000). Mesmo com a excisão dos cotilédones, verifica-se que o uso do ácido cítrico não se faz necessário, uma vez que não foi observada a presença de oxidação nos eixos embrionários em nenhum dos tratamentos. De acordo com Cordeiro et al. (2002), o antioxidante polivinilpirrolidona (PVP) foi altamente eficiente no controle da oxidação em sementes de paricá, entretanto, os autores não estudaram a germinação das sementes em meio desprovido de PVP.

Também foi constatado que o meio MS com as concentrações dos sais reduzidas a metade não diferiram significativamente para as variáveis analisadas em relação ao meio MS normal. Por sua vez, Souza et al. (2003) ao estudarem a germinação in vitro de arnica (Lychnophora pinaster Mart), verificaram que meios menos concentrados permitem melhor germinação dos embriões e maior comprimento da parte aérea.

De acordo com a análise de variância (Tabela 3), houve diferença significativa ao nível de $1 \%$ de probabilidade entre os tratamentos, em relação ao peso de massa fresca da haste caulinar e da raiz, e plântulas com o primeiro par de folhas.

Nos tratamentos contendo $\mathrm{AG}_{3}$, foram observados os maiores pesos da massa fresca da haste caulinar e da raiz, diferindo significativamente dos demais tratamentos, independentes da presença ou ausência de ácido cítrico, conforme observa-se na Tabela 4.

O tratamento com eixos embrionários inoculados em meio MS com as concentrações reduzidas à metade apresentaram o maior porcentual de plântulas com o primeiro par de folhas após 30 dias de cultivo (67\%), mas não houve diferença significativa dos meios de cultivo $1 / 2 \mathrm{MS}+$ ácido cítrico; MS; e MS + ácido cítrico. O tratamento menos eficiente foi o que continha $1 / 2 \mathrm{MS}+$ ácido cítrico $+\mathrm{AG}_{3}, \mathrm{o}$ qual não contribuiu para a formação de folhas, não diferindo estatisticamente do tratamento em que foi utilizado meio MS normal + ácido cítrico $+\mathrm{AG}_{3}$, que apresentou $6 \%$ das plântulas possuindo o primeiro par de folhas (Tabela 4).

Chagas et al. (2005) cultivaram embriões imaturos de citros na presença de 0,$01 ; 0,1 ; 1$ e $10 \mathrm{mg} . \mathrm{L}^{-1}$ de $\mathrm{AG}_{3}$ e obtiveram o maior peso de massa fresca de plântulas, no meio contendo $0,01 \mathrm{mg} . \mathrm{L}^{-1}$ desse regulador de crescimento. Esses autores verificaram que houve necessidade de baixas concentrações de giberelina para melhor desenvolvimento de embriões de citros, fato que deve ser estudado em eixos embrionários de paricá. 
Tabela 3 - Resumo da análise de variância para peso da massa fresca da haste caulinar (PMFHC), peso da massa fresca da raiz (PMFR) e porcentual de plântulas com o primeiro par de folhas (1PF).

\begin{tabular}{lccccccc}
\hline \multicolumn{1}{c}{ C.V. } & G.L. & \multicolumn{3}{c}{ Q.M. } & \multicolumn{2}{c}{ F } \\
\hline & & PMFHC & PMFR & 1 PF $^{1}$ & PMFHC & PMFR & 1 PF $^{1}$ \\
\hline Tratamentos & 5 & 37462,4 & 53837,6 & 0,9959 & $14,5 * *$ & $12,8 * *$ & $7,5^{* *}$ \\
Resíduo & 36 & 2566,0 & 4214,2 & 0,1335 & & & \\
\hline Média & & 239,1 & 118,52 & 0,49 & & & \\
\hline
\end{tabular}

** Significativo ao nível de $1 \%$ de probabilidade, pelo teste $\mathrm{F}$.

${ }^{1}$ Dados transformados para $\operatorname{arcsen}(\mathrm{X} / 100)^{1 / 2}$.

Tabela 4 - Peso da massa fresca (PMF) da haste caulinar e da raiz e, porcentual de plântulas oriundas de eixos embrionários de paricá que apresentaram o $1^{\circ}$ par de folhas aos 30 dias de cultivo, em diferentes composições do meio MS.

\begin{tabular}{lccc}
\hline $\begin{array}{c}\text { Composição do meio } \\
\text { de cultura }\end{array}$ & \multicolumn{2}{c}{ PMF $(\mathrm{mg})$} & $\begin{array}{c}\text { Plântulas com o } 1^{\circ} \text { par de } \\
\text { folhas }(\%)\end{array}$ \\
\cline { 2 - 3 } $1 / 2 \mathrm{MS}$ & Haste Caulinar & $85,0 \mathrm{~b}$ & $66,7 \mathrm{a}$ \\
$1 / 2 \mathrm{MS}+\mathrm{AC}$ & $198,3 \mathrm{~b}$ & $68,0 \mathrm{~b}$ & $40,0 \mathrm{ab}$ \\
$1 / 2 \mathrm{MS}+\mathrm{AC}+\mathrm{AG}_{3}$ & $198,0 \mathrm{~b}$ & $213,0 \mathrm{a}$ & $0,0 \mathrm{c}$ \\
$\mathrm{MS}$ & $320,0 \mathrm{a}$ & $50,0 \mathrm{~b}$ & $33,3 \mathrm{abc}$ \\
$\mathrm{MS}+\mathrm{AC}$ & $218,6 \mathrm{~b}$ & $48,9 \mathrm{~b}$ & $40,0 \mathrm{ab}$ \\
$\mathrm{MS}+\mathrm{AC}+\mathrm{AG}_{3}$ & $218,6 \mathrm{~b}$ & $246,0 \mathrm{a}$ & $5,7 \mathrm{bc}$ \\
\hline
\end{tabular}

Médias seguidas por letras distintas entre si comparam os tratamentos, ao nível de $5 \%$ de probabilidade pelo Teste de Tukey. MS: meio de cultura Murashige \& Skoog (1962); AC: ácido cítrico; $\mathrm{AG}_{3}$ : ácido giberélico.

\section{CONCLUSÕES}

Os eixos embrionários de paricá podem ser cultivados em meio MS com metade das concentrações dos sais, não sendo necessária a adição de ácido cítrico.

A presença de $3 \mathrm{mg} . \mathrm{L}^{-1}$ de $\mathrm{AG}_{3}$ afetou o desenvolvimento das plântulas de paricá, havendo necessidade de estudos com concentrações reduzidas desse regulador de crescimento.

\section{REFERÊNCIAS BIBLIOGRÁFICAS}

ALVARENGA, A. A. de. Substâncias de crescimento e regulação do desenvolvimento vegetal. Lavras: ESAL, 1990. $56 \mathrm{p}$.

ANDRADE, M. W. de; LUZ, J. M. Q.; LACERDA, A. S.; MELO, P. R. A. de. Micropropagação da aroeira (Myracrodruon urundeuva Fr. All). Ciência e Agrotecnologia, Lavras, v. 24, n. 1, p. 174-180, jan./mar. 2000.

CARVALHO, G. R.; PASQUAL, M.; GUIMARÃES, R. J.; MENDES, A. N. G.; ANTUNES, L. E. C.; SILVA, A. T. da.
Efeito do ácido giberélico e benzilaminopurina no crescimento in vitro de embriões do cafeeiro cv. Acaia. Pesquisa Agropecuária Brasileira, Brasília, v. 33, n. 6, jun. 1998.

CHAGAS, E. A.; PASQUAL, M.; RAMOS, J. D.; PIO, L. A. S.; DUTRA, L. F.; CAZETTA, J. O. Cultivo de embriões imaturos de citros em diferentes concentrações de carvão ativado e ácido giberélico. Ciência e Agrotecnologia, Lavras, v. 29, n. 6, p. 1125-1131, nov./dez. 2005.

CORDEIRO, I. M. C. C. Respostas morfogenéticas in vitro de paricá (Schizolobium amazonicum Huber, Ex Ducke). 2002. 61 f. Dissertação (Mestrado em Ciências Florestais) - Faculdade de Ciências Agrárias do Pará, Belém, 2002.

CORDEIRO, I. M. C. C.; LAMEIRA, O. A.; LOPES, S. C.; RIOS, M. S. Germinação in vitro de paricá. Biotecnologia Ciência \& Desenvolvimento, v. 27, jul./ago. 2002.

FALESI, I. C.; SANTOS, J. C. dos. Produção de mudas de paricá (Schizolobium amazonicum Huber). Belém: FCAP, 1996. 16 p. (Informe técnico, 20). 
FERREIRA, D. F. SISVAR Sistemas de Análises de Variância para dados balanceados: programa de análises estatísticas e planejamento de experimentos. Versão 4.3. Lavras: UFLA, 2002.

FORTES, G. R. de L. Calogênese e organogênese in vitro de macieira (Malus spp) afetados por fatores físicos, químicos e biológicos. 1992. 163 f. Tese (Doutorado em Fitotecnia) - Universidade Federal de Viçosa, Viçosa, 1992.

GEORGE, E. F. Plant propagation by tissue culture: the technology. 2. ed. Edington: Exegetics, 1993. part 1, 574 p.

GRATTAPAGLiA, D.; MACHADO, M. A. Micropropagação. In: TORRES, A. C.; CALDAS, L. S.; BUSO, J. A. (Eds.). Cultura de tecidos e transformação genética de plantas. Brasília, DF: Embrapa-SPI; EmbrapaCNPH, 1998. v. 1, p. 183-260.

HU, C. Y.; FERREIRA, A. G. Cultura de embriões. In: TORRES, A. T.; CALDAS, L. S.; BUSO, J. A. (Eds.). Cultura de tecidos e transformação genética de plantas. Brasília, DF: Embrapa/SPI, 1998. p. 371-393.

KAUR, R.; SHARMA, N.; KUMAR, K.; SHARMA, D. R.; SHARMA, S. D. In vitro germination of walnut (Juglans regia L.) embryos. Scientia Horticulturae, Champaign, v. 109, p. 385-388, 2006.

KOCHBA, J.; BUTTON, J.; SPIEGEL-ROY, P.; BORNMAN, C. H.; KOCHABA, M. Stimulation of rooting of citrus embryoids by gibberellic acid and adenini sulphate. Annals of Botany, New York, v. 38, p. 795-802, 1974.

MURASHIGE, T.; SKOOG, F. A revised medium for rapid growth and bioassays with tobacco tissue cultures. Physiologia Plantarum, Copenhagen, v. 15, p. 473-497, 1962.

PASQUAL, M.; PINTO, J. E. B. P. Cultura de embriões. Notícias da Associação Brasileira de Cultura de Tecidos de Plantas, Brasília, v. 9, p. 2-12, ago. 1988.

PIERIK, R. L. M. Cultivo in vitro de las plantas superiores. 3. ed. Madrid: Mundi, 1990. 326 p.

RIBEIRO, V. G.; SANÁBIO, D.; SOUZA, C. N. de; LOPES, P. S. N.; BOCARDO, M. R.; PASQUAL, M. Efeitos de ácido giberélico e carvão ativado no cultivo in vitro de Citrus limonia Osb. X Poncirus trifoliata (L.) Raf. Pesquisa Agropecuária Brasileira, Brasília, v. 35, n. 1, p. 27-30, jan. 2000.

SOUZA, A. V.; PINTO, J. E. B. P.; BERTOLUCCI, S. K. V.; CORRÊAA, R. M.; CASTRO, E. M. de. Germinação de embriões e multiplicação in vitro de Lychnophora pinaster Mart. Ciência e Agrotecnologia, Lavras, p. 1532-1538, dez. 2003. Edição especial.

SOUSA, D. B. de; CARVALHO, G. S.; RAMOS, E. J. A. Paricá (Schizolobium amazonicum Huber ex Ducke). Manaus: INPA, 2005. 2 p. (Informativo técnico Rede Sementes da Amazônia, 13). 